\title{
Development and validation of a questionnaire to measure success in financial computing literacy
}

\author{
A. Deshpande, Ph.D., FHEA, Department of Mathematical Sciences, University of Liverpool, \\ Liverpool, UK. Email: addeshpa@gmail.com
}

\section{Abstract}

An embedded model of teaching financial computing within a course on numerical analysis in finance has been proposed recently in (Deshpande, 2017). It consists of only 10 steps that are aimed at programming beginners. These steps expect students only to be self-motivated to learn. Hence other attributes like pre-knowledge of programming and cleverness aren't expected to influence the learning outcome. Through qualitative assessment via laboratory observation this was indeed found to hold true. In order to understand the outcome of these 10 steps on a much finer scale, we develop here a questionnaire that measures success in financial computing literacy (SFCL) via quantitative assessment. Four scales were developed: self-efficacy or computing confidence, active learning strategy/pro-activeness, learning environment stimulation and an achievement goal in terms of student satisfaction. Findings of this pilot study confirm construct validity of the questionnaire. Importantly we conclude that self-motivation is not enough and that tenacity is a vital component to keep motivation going. Tenacity can be induced via providing credit for attempting steps.

Keywords: questionnaire, construct validation, success in financial computing literarcy.

\section{Introduction}

Many universities have prioritized the development and the teaching of financial computing courses in response to the increase in recruitment in the financial services sector.This has been done primarily under the umbrella of financial mathematics/engineering. (Kyng et al, 2013) in fact mention that financial services employers rate software skills as important and would like their employees to be more highly skilled in the use of software. A course on financial computing is generally taught separately, before a course on numerical analysis of financial derivatives (or financial numerics). The logic behind this ordering is that the student can then do the financial computing required within financial numerics. However as argued by (Deshpande, 2017) this lacks inclusiveness in terms of a student's ability. Hence, he proposes an embedded inclusive model of introducing financial computing within financial numerics via only 10 steps. These steps as such do not test any logical construct and hence do not need any prior programming background. It has been claimed therein that these steps achieve "financial computing literacy" akin to what "computer literacy" is. It acknowledges that the success in financial computing via 10 steps is primarily due to:

(i) self-efficacy or computing confidence, whereby students believe in their own ability to perform well in financial computing, irrespective of whether they had any prior programming experience cf. (Cretchley et al.,1999), and also refer to (Fogarty et al., 2001) and references therein;

(ii) active learning strategies/pro-activeness, in which students take an active role in using a variety of strategies to construct new knowledge based on their previous understanding. Note that this scale does not relate to intrinsic self-motivation; 
(iii) learning environment stimulation, which encompasses the in-class learning environment surrounding students, such as the curriculum, teacher's approach to teaching and pupil interaction influencing students' motivation in learning financial computing and

(iv) student achievement goal or satisfaction.

These four scales have been borrowed from the science learning questionnaire study of (Tuan, Chin \& Shieh, 2005) and (Fogarty et al., 2001). The main aim of that study had been to assess the construct validity of the questionnaire in terms of these scales, that relate to the structure of the 10 steps with students' attitudinal background and concluding with comments in support of success in financial computing literacy (SFCL).

\section{Research Design}

\subsection{Participants}

The participants/students were financial mathematics postgraduate students at a UK-based university. These students came from varied backgrounds like engineering, business and mathematics. The SFCL survey questionnaire detailed at the end of this article was handled online. In total 13 out of 14 students ( 7 males) enrolled in the course completed the survey at the end of conducting the 10 steps/exercises. Though enrollment in master's programs is expectedly small and consequently so is this sample, for this pilot study it is however well representative with almost equal participation by gender and mature students, enough to expect a robust response validating much of what was observed in the qualitative assessment noted in (Deshpande, 2017).

\subsection{Materials}

A total of 30 questions were developed with regards to four out of the six scales from (Tuan, Chin \& Shieh, 2005).

Broadly speaking these refer to:

Self-efficacy: Students believe in their own belief to perform well in computing tasks.

Active learning strategies: Students take an active role in using a variety of strategies to construct new knowledge based on their previous understanding.

Learning environment stimulation: In the class, learning environment surrounding students, such as curriculum and pupil interaction influenced students' motivation in science learning.

Achievement goal: Students feel satisfaction as they increase their competence and achievement during the computing laboratory exercise.

We note that we do not incorporate the remaining two of the six scales from (Tuan, Chin \& Shieh, 2005), viz. Science learning value and Performance goal, since these are not specific to our domain of study as it chiefly revolves around motivation in science learning via competition. This is so because, in our case, students inarguably are aware of the value of financial computing and the structure of our 10 steps do not involve or encourage learning via competition. Additionally, items under the self-efficacy scale have been borrowed from (Fogarty et al., 2001) as it desirably relates to computing confidence. In the scale relating to active learning strategies, we incorporate questions that consider both constructivists learning and deep learning strategies. The latter is important since the first three of the 10 steps that we propose start with stand and deliver style instruction, which (Ramsden, 2003) argues encourages surface learning. Hence, we expect to know how our remaining 
7 steps fare in terms of deep learning strategies. All scales except self-efficacy had a mixture of fairly balanced positive and negatively worded statement items. The majority of questions on the selfefficacy scale have a negative orientation, thus reflecting the primary concern of most educators, which is a possible handicapping effect of negative attitudes towards computers and mathematics (Fogarty et al., 2001). Also, the questions were worded so that the respondents think about the statements rather than respond automatically. It also minimizes the effect of a response set towards either agreement or disagreement with whatever statement is made (Moser and Kalton, 1980). All items employed a Likert-style response format, with options ranging from 5 (Strongly agree), 4 (Agree), 3 (Neutral), 2 (Disagree), to 1 (Strongly disagree).

\section{Results}

The ability of the questionnaire to individually differentiate between motivation levels vis-à-vis the scales was measured using one-way analysis of variance (cf. Table 1). Here data is presented in mean (standard deviation) format. As seen from Table 1, low $(L)$ motivation level students performed below those categorized with High $(\mathrm{H})$ and Moderate $(\mathrm{M})$ motivation levels. All these levels are significantly different when information of all items on every scale of the questionnaire are collated as seen in the last column $(p<0.002)$. Self motivation levels govern outcome in the self-efficacy scale $(p<0.002)$ as expected. Success in the SFCL as captured in the achievement goal (which is same for $\mathrm{H}, \mathrm{M}$ and less for $\mathrm{L}$ ) indicates that self-motivation plays a significant role in the outcome of SFCL. The $\mathrm{M}$ level students experience positive influence from the learning environment in comparison to $\mathrm{H}$ and $\mathrm{L}$ levels. This is expected since $\mathrm{H}$ level students are observed to be mostly self-focussed and learning environment stimulation had not had much impact on them, while $L$ level students sitting mainly close together with like-minded $L$ colleagues did not benefit much from the discussion, they had within themselves during the SFCL exercise. Similar reasoning can be reported under the scale of Active learning strategy. Though the numbers for $H$ and $L$ are encouraging they are lower than $M$ type students. Note that the associated $\mathrm{F}$ ratios for these two scales aren't statistically significant in comparision to the remaining scales but are in reality close to our observation related to attitudinal difference that was also reported in (Weimar, 2013). Another belief is whether these two scales could be viewed as a single construct, since an active learning strategy is aided by the learning environment stimulation, and it is hard to detect perception to environment stimulation within a short span such as the one semester over which the SFCL is conducted. This is in fact reinforced by smaller values of the partial $\eta^{2}$ in Table 2 (viz. 0.14 and 0.17 ). However, we think that even transient emotional reaction to the learning environment stimulation scale may itself strengthen and deepen into firm attitudes if reinforced (Mandler, 1984). Hence, we will keep these two scales.

Table 1. One-way analysis of variance of high, medium and low-motivation level towards responses on the SFCL questionnaire.

$\begin{array}{cccccc}\text { Motivation } & \text { Self-efficacy } & \begin{array}{c}\text { Learning } \\ \text { environ. stim. }\end{array} & \begin{array}{c}\text { Achievement } \\ \text { goal }\end{array} & \begin{array}{c}\text { Active } \\ \text { learning } \\ \text { strategy }\end{array} & \text { Total Qns. } \\ \text { High } & 39.00(0.00) & 10.00(0.00) & 16.00(0.00) & 21.00(0.00) & 11.07(0.00) \\ \text { Moderate } & 27.50(3.50) & 12.00(0.00) & 16.00(1.41) & 23.00(1.41) & 10.76(0.16) \\ \text { Low } & 24.22(4.11) & 9.88(2.08) & 11.88(1.69) & 20.22(2.99) & 8.90(0.82) \\ F & 12.08 & 1.063 & 9.40 & 0.867 & 11.62 \\ & p<0.002 & p=0.381 & p=0.005 & p=0.45 & p=0.002\end{array}$


The results in table 2 discuss internal reliability of the questionnaire. Cronbach's alpha reliability coefficient for each scale, using an individual student as the unit of analysis, ranged between 0.24 and 0.85 and were estimated to be in general satisfactory. The discriminative validity or mean correlation with other scales refers to the extension to which each scale measured a dimension different from that measured by any other scale. In the SFCL the validity was close knit and ranged from 0.16 to 0.37 , showing some overlapping with other scales. This feature was also captured as dicussed following Table 1 and only gets reinforced by the partial $\eta^{2}$ scores, which ranged from 0.14 to 0.70 in Table 2. Two scales viz. achievement goal and self-efficacy enjoyed the lion's share of the proportion of this measure which was 0.65 and 0.70 respectively, in contrast to the remaining two scales.

\section{Table 2. Internal consistency (Cronbach alpha coefficient) and discriminative validity (mean correlation with other scales).}

\begin{tabular}{|c|c|c|c|c|c|c|c|}
\hline \multirow[t]{2}{*}{ Scale } & \multirow[t]{2}{*}{ Item no. } & \multirow[t]{2}{*}{ Mean } & \multirow[t]{2}{*}{$\begin{array}{l}\text { Std. } \\
\text { dev. }\end{array}$} & \multicolumn{2}{|c|}{ Cronbach alpha } & $\begin{array}{l}\text { Partial } \\
\text { analysis } \\
\text { of var. } \\
\left(\eta^{2}\right)\end{array}$ & $\begin{array}{c}\text { Mean } \\
\text { correlatior } \\
\text { with other } \\
\text { scales }\end{array}$ \\
\hline & & & & Individual & $\begin{array}{l}\text { Class } \\
\text { mean }\end{array}$ & & \\
\hline Self-efficacy & Q1-Q12 & 27.00 & 2.63 & 0.85 & 0.80 & 0.70 & 0.24 \\
\hline $\begin{array}{l}\text { Active } \\
\text { learning } \\
\text { strategy }\end{array}$ & Q13-Q20 & 20.76 & 2.68 & 0.46 & 0.42 & 0.14 & 0.24 \\
\hline $\begin{array}{l}\text { Learning } \\
\text { environ. } \\
\text { stimulation }\end{array}$ & Q21-Q25 & 10.23 & 1.87 & 0.24 & 0.27 & 0.17 & 0.16 \\
\hline $\begin{array}{l}\text { Achievement } \\
\text { goal }\end{array}$ & Q26-Q30 & 13.15 & 2.44 & 0.62 & 0.59 & 0.65 & 0.37 \\
\hline Total Qns & Q1-Q30 & 71.15 & 9.56 & 0.81 & 0.80 & 0.70 & --- \\
\hline
\end{tabular}

The pattern matrix (see Table 3) derived from the factor analysis performed using principle axis factoring with oblique (oblimin) rotation provides 8 factors/ components. In Table 3, all components except the last one has at least one item from either self-efficacy and or achievement goal. The $8^{\text {th }}$ component has item 18 and item 19 (see Appendix for details) worded similarly, but one in a positive spirit while the other is in a negative spirit to discount biasedness in response. Hence in general selfefficacy and achievement goal are significant over the other two scales. We emphasized the role of "self-motivation" in SFCL (Deshpande, 2017). However, based on the outcome of this exercise, we infer that one also needs the less emphasized learning environment stimulation to instigate "proactiveness/active learning strategy" for reaping major benefits of SFCL. Hence one could induce it by providing contributing credit towards all the 10 steps or maybe first few steps, one for the middle step i.e. Exercise 6 and one at the end viz. Exercise 10. This will likely enhance the significance of active learning strategy through tenacity. 
Table 3. Factor pattern matrix of items in SFCL questionnaire $(n=13)$

\begin{tabular}{|c|c|c|c|c|c|c|c|c|}
\hline \multicolumn{9}{|c|}{ Pattern Matrix ${ }^{a}$} \\
\hline & \multicolumn{8}{|c|}{ Component } \\
\hline & 1 & 2 & 3 & 4 & 5 & 6 & 7 & 8 \\
\hline SelfeffQ11 & 0.998 & & & & & & & \\
\hline SelfeffQ12 & 0.881 & & & & & & & \\
\hline SelfeffQ4 & 0.757 & & & & & & & \\
\hline LearnenvirstimQ22 & -0.736 & & & & & & & \\
\hline SelfeffQ9 & 0.627 & & & & & & & \\
\hline SelfeffQ2 & & 0.879 & & & & & & \\
\hline ActLearnSratQ14 & & 0.825 & & & & & & \\
\hline ActLearnSratQ13 & & 0.785 & & & & & & \\
\hline LearnenvirstimQ25 & & & 0.938 & & & & & \\
\hline SelfeffQ8 & & & 0.756 & & & & & \\
\hline LearnenvirstimQ24 & & & 0.608 & & & & & \\
\hline LearnenvirstimQ21 & & & & -0.872 & & & & \\
\hline SelfeffQ7 & & & & 0.833 & & & & \\
\hline AchivgoalQ27 & & & & 0.644 & & & & \\
\hline ActLearnSratQ15 & & & & 0.524 & & & & \\
\hline SelfeffQ5 & & & & 0.484 & & & & \\
\hline ActLearnSratQ17 & & & & & 0.876 & & & \\
\hline SelfeffQ3 & & & & & 0.711 & & & \\
\hline LearnenvirstimQ23 & & & & & & 0.990 & & \\
\hline ActLearnSratQ20 & & & & & & -0.702 & & \\
\hline AchivgoalQ26 & & & & & & 0.488 & & \\
\hline SelfeffQ10 & & & & & & 0.486 & & \\
\hline SelfeffQ1 & & & & & & 0.470 & & \\
\hline AchivgoalQ28 & & & & & & 0.447 & & \\
\hline SelfeffQ6 & & & & & & & -0.733 & \\
\hline AchivgoalQ29 & & & & & & & -0.710 & \\
\hline ActLearnSratQ16 & & & & & & & -0.641 & \\
\hline AchivgoalQ30 & & & & & & & -0.439 & \\
\hline ActLearnSratQ18 & & & & & & & & 0.975 \\
\hline ActLearnSratQ19 & & & & & & & & 0.618 \\
\hline
\end{tabular}




\section{Conclusion}

We test the efficacy of the 10 steps proposed in (Deshpande, 2017) by validating it via a questionnaire consisting of 30 questions that are divided into 4 scales. Positive outcomes to these 10 steps validated through the scale of computing confidence and achievement goal were however not strongly correlated with the scales of pro-activeness and learning environment stimulation. However, there is some evidence in support of including these two scales as an intrinsic part of selfmotivational attitudes and group dynamics. One can ascertain from the analysis of Table 1, that low motivation students fared poorly in these two scales while high motivation students did not have much performance incentive due to gaining no credit for doing the 10 steps. Providing credit to the first few foundational yet simpler questions of (Deshpande, 2017) may enhance learning environment stimulation. This may then induce tenacity in low motivated students to build up proactiveness. A similar outcome is anticipated for high motivated students. The results so obtained, in totality, also suggest one avenue of future investigation: We would like to know how "being clever" (Coughlan, 2016) influences success in implementation of these 10 steps. Though being clever helps, we believe that the success in implementation of these 10 steps does not and should not need any kind of cleverness. Our future aim would then be to also run these 10 steps for university students in countries ranked highly in the Organisation for Economic Co-operation and Development (OECD) index. We can then compare the implementation outcome vis-à-vis the UK. We anticipate similar outcomes amongst all participant OECD countries thus establishing invariance of SFCL towards predisposed cleverness.

\section{References}

Coughlan, S. (2016). Which country really has the cleverest students? BBC report, Available at: http://www.bbc.co.uk/news/business-37649892 [Accessed 29 December 2017].

Cretchley, P., Harman, C., Ellerton, N., and Fogarty, G. (1999). Computation, exploration, visualisation: Reaction to MATLAB in First Year Mathematics. 2nd Australian Symposium on Modern Undergraduate Mathematics, Proserpine, Qld, Australia.

Deshpande, A. (2017). Financial computing literacy: 10 steps. MSOR connections, 16(1), pp. 4552.

Fogarty, G., Cretchley, P., Harman, C., Nerida E. and Konki, N. (2001). Validation of a questionnaire to measure mathematics confidence, computer confidence, and attitudes towards the use of technology for learning mathematics. Math Ed Res J, 13 (2), pp. 154-160.

Huang, W., Huang, W., Diefes-Dux, H. and Imbrie, P. K. (2006). A preliminary validation of Attention, Relevance, Confidence and Satisfaction model-based Instructional Material Motivational Survey in a computer-based tutorial setting. British Journal of Educational Technology, 37, pp. 243-259.

Kyng, T., Tickle, L. and Wood, L. (2013). Perceptions of the software skills of graduates by Technology employers in the financial services industry. International Journal of Mathematical Education in Science, 44 (8), pp. 1224-1238.

Mandler, G. (1998). Affect and learning: Causes and consequences of emotional interactions. In D. A. Grouws (Ed.), Handbook on research on mathematics teaching and learning New York: Macmillan. pp. 575-596. 
Moser, C. A., and Kalton, G. (1980). Survey methods in social investigations. 2nd ed. London: Heinmann.

Ramsden, P. (2003). Learning to teach in higher education. 2nd edn. London: Routledge Falmer.

Tuan, H-L., Chin, C-C. and Shieh, S-H. (2005). The development of a questionnaire to measure students' motivation towards science learning. International Journal of Science Education, 27(6), pp. 639-654.

Weimar, P. (2013). Better Group Work Experiences Begin with How the Groups Are Formed. Available at: http://www.facultyfocus.com/articles/teaching-professor-blog/better-group-workexperiences-begin-with-how-the-groups-are-formed// [Accessed 28 February 2017].

\section{Appendix: SFCL survey questionnaire}

\section{Self-efficacy or computing confidence.}

1. I have less trouble learning how to program using MATLAB than I do other things.

2. When I have difficulties using MATLAB, I know I can handle them.

3. I am not what I would call a computer programmer.

4. It takes me much longer to understand how to code in MATLAB than the average person.

5. I have never felt myself able to learn how to code in MATLAB.

6. I enjoy trying new ways to program in MATLAB.

7. I find MATLAB programming frightening.

8. I find many aspects of MATLAB programming interesting and challenging.

9. I don't understand how some people can seem to enjoy MATLAB programming.

10. I have never been excited about using computers.

11. I find doing MATLAB programming confusing.

12. I am nervous that I am not good enough with MATLAB programming to be able to use them in financial computing.

Active learning strategy or pro-activeness.

13. When learning new MATLAB programming concepts, I attempt to understand them.

14. When learning new MATLAB programming concepts, I connect them to my previous experiences.

15. When I do not understand a MATLAB programming concept, I find relevant resources that will help me. 
16. When I do not understand a MATLAB programming concept, I would discuss it with my instructor or other students to clarify my understanding.

17. During the learning process, I attempt to make connections between the concepts that I learn.

18. When I make a programming mistake, I try to find out why.

19. When I meet MATLAB programming concept that I do not understand, I still try to learn them.

20. When new programming concepts that I have learned conflict with my previous understanding, I try to unerstand why.

\section{Learning environment stimulation}

21. I am willing to participate in this computing lab because the content is exciting.

22. I am willing to participate in this computing lab because the instructor uses a variety of teaching methods.

23. I am willing to participate in this computing lab because the instructor does not put a lot of pressure on me.

24. I am willing to participate in this computing lab because it is challenging.

25. I am willing to participate in this computing lab with a laptop because it allows me to consult my colleague(s) next to me.

\section{Achievement goal or student satisfaction}

26. I feel most fulfilled when I feel confident about the content in the computing lab.

27. During a computing lab, I feel most fulfilled when the teacher accepts my ideas.

28. During a computing lab, I feel most fulfilled when I am able to solve a difficult problem.

29. My MATLAB programming skills improved as I went completing the 10 steps.

30. I am now more confident than before of using Pseudo codes to do MATLAB programming. 